\title{
Best Paper Awards for 2015
}

During 2013, Birkhäuser (Springer) instituted three Best Paper Awards for papers published in Circuits, Systems and Signal Processing (see the announcement in the October 2013 issue of CSSP). A call for nominations for these awards was sent out to all the Associate Editors inviting them to nominate those papers published in 2014 or 2015 in CSSP, which should be considered for these awards. This call was also posted on the CSSP Web site. A total of seven papers were nominated. A Selection Committee consisting of Dr. P. V. Ananda Mohan, Electronic Corporation of India Limited, Bangalore, India; Dr. A. M. Soliman of Cairo University, Egypt; and Dr. Pramod Kumar Meher of Nanyang University of Technology, Singapore, was set up to select the best paper in each category for the year 2015. The recipients for the Armen H. Zemanian Best Paper Award, given for the best paper published in 2015 in the areas of Circuits and Systems, are Michał Tadeusiewicz, Andrzej Kuczyński, and Stanisław Hałgas for their paper entitled "Catastrophic Fault Diagnosis of a Certain Class of Nonlinear Analog Circuits," published in the February 2015 issue, pp. 353375. The recipients for the Sydney R. Parker Best Paper Award, given for the best paper published in 2015 in the area of Signal Processing, are Fatema Tuz Jhohura, Tamanna Howlader, and S. M. Mahbubur Rahman for their paper "Bayesian Fusion of Ensemble of Multifocused Noisy Images," published in the July 2015 issue, pp. 2287-2308. The former paper was also chosen for the M.N.S. Swamy Best Paper Award, which is given for the best paper published in 2014 or 2015 irrespective of the subject area. Each of these awardees will receive a certificate and a cash prize. I would like to congratulate the recipients of the three awards. I would also like to take this opportunity to thank all the nominators and especially the members of Selection Committee for their time and effort in selecting the winners for the various awards.

M.N.S. Swamy

Editor-in-Chief, CSSP 